\title{
Influence of molecular structure of Carboxymethyl Cellulose on High Performance Silicon Anode in Lithium-Ion Batteries
}

\author{
Chaofan Huang ${ }^{1}$, Lubing Yu ${ }^{1}$, Shuaishuai He ${ }^{1}$, Lihui Gan ${ }^{1,2,3}$, Jian Liu ${ }^{1,2,3, *}$, Zhengliang Gong ${ }^{1, *}$, \\ Minnan Long ${ }^{1,2,3}$ \\ ${ }^{1}$ College of Energy, Xiamen University, Xiamen, 361102, China \\ ${ }^{2}$ Xiamen Key Laboratory of Clean and High-valued Applications of Biomass, Xiamen University, \\ Xiamen 361102, China; \\ ${ }^{3}$ Fujian Engineering and Research Center of Clean and High-valued Technologies for Biomass, \\ Xiamen University, Xiamen 361102, China \\ *E-mail: jianliu@xmu.edu.cn, zlgong@xmu.edu.cn
}

doi: $10.20964 / 2019.05 .41$

Received: 7 Janaury 2019 / Accepted: 20 February 2019 / Published: 10 April 2019

The study aims to the preparation of bio-based binders with optimal molecular structure for electrodes and the exploration of their influence on the electrochemical performance of electrodes. At first, a series of Carboxymethyl Cellulose (CMC) with different degree of polymerization (DP) and degree of substitution (DS) were successfully prepared using the specially designed method and their physical characteristics were also investigated. Si anodes were manufactured with the CMC binders and their electrochemical performances were evaluated and compared. As a consequence, the silicon anode containing $\mathrm{CMC}$ of $\mathrm{DS}=0.38$ and $\mathrm{DP}=215$ showed the best cyclic performance $(71 \%$ of capacity maintained after the 100th cycle) due to its compatible molecular structure. It is assumed that the CMC with specially designed molecular structure plays a key role in binding the silicon particles during the cycles and weakened the volume effect.

Keywords: Carboxymethyl cellulose; Silicon anode; molecular structure; Lithium-Ion Batteries

\section{$\underline{\text { FULL TEXT }}$}

(C) 2019 The Authors. Published by ESG (www.electrochemsci.org). This article is an open access article distributed under the terms and conditions of the Creative Commons Attribution license (http://creativecommons.org/licenses/by/4.0/). 